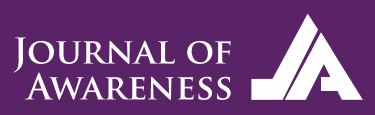

8
Journal of Awareness

Volume / Cilt: 6, Issue / Sayl: 2, 2021, pp. 115-121

E-ISSN: 2149-6544

https://journals.gen.tr/joa

DOI: https://doi.org/10.26809/joa.6.3.03
Received / Geliș: 09.05.2021

Acccepted / Kabul: 02.07.2021

\title{
"Ahlaki olanı düşünmeyi düşünmek": bilinçli farkındalık, üstbiliş ve ahlaki üst biliş arasındaki ilişkilere yönelik bir model
}

\author{
"Thinking about thinking on the moral one": a model on the \\ relationships between mindfulness, metacognition, and moral \\ metacognition
}

\section{Gökhan Arslantürk $^{1}$ (D) Zeliha Beyza Şamyanlı \\ 1 Dr. Öğrt. Üyesi, Selçuk Üniversitesi, Psikoloji Bölümü, Konya, TÜRKIYY, e-mail: gokhan_arslanturk@hotmail.com 2 Selçuk Üniversitesi, Aile Danışmanlı̆̆ı ve Eğitimi Anabilim Dalı, Konya, TÜRKiYE, e-mail: beyzasamyanli@gmail.com}

Öz

İnsanın ayırt edici yönü sahip olduğu bilişsel kapasitedir. Bu bilişsel kapasitesi ile medeniyetler kurmuş ve ahlaki sistemler geliştirmiştir. Farkındalık bu bilişsel özellikler arasında merkezi bir konumdadır. Kendisinin ve çevresinin farkında olan insan bu sayede düşüncelerini bilebilir, izleyebilir ve düzenleyebilir. Bu çalışma bu bilişsel özellikleri ahlaki bağlamda ele almaktadır. Bu doğrultuda üstbilişin bilinçli farkındalık ve ahlaki üstbiliş arasındaki aracı rolüne dair bir model önerilmiştir. Araştırmanın katılımcıları çoğunluğu üniversite öğrencisi 220 kişiden oluşmaktadır. Araştırmanın anket ve soruları katılımcılara çevrimiçi olarak ulaştırılmıştır. Modelin test edilmesinden elde edilen bulgular bilinçli farkındalığın ahlaki üstbilişe üstbiliş aracılığıyla katkı sağladığına işaret etmektedir. Bununla birlikte bilinçli farkındalık ile ahlaki üstbiliş arasında doğrudan ilişki bulunmamaktadır. Bulgular; çalışmanın literatüre katkısı, sınırlılıkları ve gelecekteki çalışmalar için çıkarımlar ekseninde tartışıldı.

Anahtar kelimeler: Bilinçli farkındalık, üstbiliş, ahlaki üstbiliş, ahlaki farkındalık

\section{Abstract}

The distinguishing feature of human is his/her cognitive capacity. With this cognitive capacity, people established civilizations and developed moral systems. Awareness is central to these cognitive traits. People who are aware of themselves and their environment can know, monitor, and regulate their thoughts. This study addresses these cognitive features in a moral context. In this direction, a model has been proposed regarding the mediating role of metacognition between mindfulness and moral metacognition. The participants of the study consist of 220 people, most of whom are university students. The scales and questions of the research were delivered to the participants online. The findings obtained from the testing of the model indicate that mindfulness contributes to moral metacognition with mediation of metacognition. However, there is no direct relationship between mindfulness and moral metacognition. The findings were discussed in terms of the contribution of the study to the literature, its limitations, and implications for future studies.

Keywords: Mindfulness, metacognition, moral metacognition, moral awareness 


\section{GİRIŞ}

Bedia Akarsu (1975: 13) Felsefe Terimleri Sözlüğ̈̈’nde ahlakı, "Belli bir dönemde belli insan topluluklarınca benimsenmiş olan, bireylerin birbirleriyle ilişkilerini düzenleyen törel davranış kurallarının, yasalarının, ilkelerinin toplamı" olarak tanımlar. Bu temel davranış kuralları, yasalarının ya da ilkelerinin nasıl temellendirildiği, yani "neye göre" ve "kime göre" oluşu geniş bir çeşitlilik arz etmektedir. Üzerinde daha geniş mutabakatların olduğu ahlaki meselelerden politik kamplaşmalara yol açan ahlaki tartışmalara uzanan bir yelpazede ahlaki olan ve olmayan ayrımı tartışılabilir. Bununla birlikte neyin ahlaki olduğunun ötesinde ahlaki olanı neyin belirlediği daha önemli görünmektedir. Zira daha geniş bir uzlaşının olduğu söylenebilecek bir başkasına zarar vermeme ya da zor durumda olan birinin ihtiyacını giderme gibi ahlaki konuların hangi değişkenler tarafından belirlendiğini bilmek insanlık için önemlidir. Böylelikle ahlak üzerine konuşmakla kalmayıp ahlaki olanın inşası üzerine kafa yormak olanaklı hale gelebilir.

Bu noktada bir diğerinin ihtiyacını gidermek ya da bilinçsizce bir başkasına zarar vermek gibi durumların merkezinde yer alan önemli bir kavramdan söz edilebilir: ahlaki farkındalık (moral awareness). Ahlaki davranışla sonuçlanan ahlaki karar verme sürecinin ilk adımı ahlaki sorunun farkına varmak yani ahlaki farkındalıktır (Butterfield vd., 2000; Drumwright vd., 2015). Bireyler bir durumun ahlaki yönünün farkında olmadıklarında verdikleri kararlar genelde ahlaki olmaktan çok bireysel yarar odaklı olmaktadır (Street vd., 2001). Diğerinin iyiliğine yönelik olumlu davranışlarla ilgili alan yazının önemli kavramları olan toplum yanlısı davranış ya da özgecilik kuram ve araştırmalarında da farkındalığa özel bir vurgu göze çarpmaktadır. Alanın en bilinen yaklaşımlarından empati-özgecilik hipotezi, empatinin bireyi özgeci davranışa götürdüğü süreci diğerinin ihtiyacını algılamak ile başlatmaktadır (Batson, 2011). Schwartz (1977) da değerlerin ya da içselleştirilmiş normların bireyleri zor durumda olan birine yardım etmeye sevk ettiği sürecin ilk adımını yardım ihtiyacının farkında olmak olarak resmetmiştir. Yardıma ihtiyacı olan birini "fark edememek" -diğer tüm özgeci niyet ve güdülere sahip olsanız da- yardım davranışının ortaya çıkmasını engellemektedir (Darley ve Batson, 1973). Öyleyse bu farkındalık sürecine yakından göz atmak gerekmektedir.
Farkındalık ya da farkında olmak dediğimizde bilinç, dikkat, bellek gibi bilişsel bir sürece işaret ediyoruz ve bu bilişsel süreçlerin birbirleri ile tamamen bağlant1sız olmadığı açıktır (bk. Goldstein, 2013). Bu açıdan, farkındalığın diğer bilişsel süreçlerle temas halinde olduğu özgün bir deneyim türü bilinçli farkındalıktır (mindfulness). Bilinçli farkındalık kişinin kendi iç durumlarına ve çevresine yönelik artmış bir farkında olma durumudur (VandenBos, 2015). Şimdiki zamana ve mevcut bağlama daha duyarlı hale gelmeyi sağlayan bu deneyim kişinin çevresindeki yeni şeylere, ayrım ve ayrıntılara daha güçlü bir dikkat yöneltmesini sağlayan bir dahil olma sürecidir (Langer, 2007). Bu farkındalık ve dikkatin âna odaklanması ahlaki kararlarla da ilintilidir. Diğer bir deyişle bilinçli farkındalık ahlaki karar verme sürecinde de rol oynamaktadır. Buna göre daha yüksek bilinçli farkındalık düzeyine sahip bireyler ahlaki ihlallere daha az meyletmektedirler (Ruedy ve Schweitzer, 2010).

Farkındalık ekseninden bilişsel süreçleri ele aldığımızda ilişkili bir diğer kavram üstbiliştir. Bir anlamda "bilişler hakkında düşünmek" ya da "düşünmeyi düşünmek" olarak tanımlayabileceğimiz (MacLin, 2007: 564) üstbiliş (metacognition), kişinin kendi bilişsel süreçlerinin farkında olması ve bu süreçleri yönetme çabasını karşılayan bir kavramdır (VandenBos, 2015). Kişinin kendi düşünce süreçleri ve bilgisi hakkındaki farkındalığını içeren bu kavram, sorunları çözmede ve yeni şeyleri anlamada bireye denetim sağlar (Matsumoto, 2009). Üstbiliş, ahlaki karar verme sürecinde karşılaşılan ikilemleri çözmede bireylere düşünceyi izleme ve yönlendirme şansı sunarak sürece anlamlı katkı yapan bilişsel bir özelliktir (Duruk vd., 2020). Üstbilişsel etkinlikler alan bazlı incelenebilir. Diğer bir deyişle çeşitli alanlara ilişkin üstbilişlerden söz edilebilir (McMahon ve Good, 2015). Bu noktada üstbilişsel süreçlerin özel bir türü olarak ahlaki bilgi ve öğrenmelerimize ilişkin üstbilişsel faaliyetlerimiz ahlaki üstbiliş olarak tanımlanır ve ahlak ile ilgili sözü edilen farkındalık odaklı bilişsel süreçlerin önemli bir parçasıdır (Cheruvalath, 2019). Ahlaki üstbiliş, kişinin ahlaki muhakemeye eşlik eden bilişsel süreçlerini izlemesi, düşünmesi, değiştirmesi ve düzenlemesine olanak tanır (McMahon ve Good, 2015; Narvaez, 2010).

\section{MEVCUT ÇALIŞMA}

Üstbiliş tanımından esinle ahlakla ilgili bilişsel seyri farkında olmak, düşünmek, düşünmeyi düşünmek, ahlaki olanı düşünmeyi düşünmek ve ahlaki olanın 
farkına varmak şeklinde özetleyebiliriz. Bilinçli farkındalık ve üstbilişe karşılık gelen deneyimler dikkate alındığında yakından ilişkili kavramlar oldukları düşünülmektedir. Kişinin kendisine ve çevresine yönelik artmış bir farkındalığın kendi zihinsel süreçleri hakkında da düşünmeye sevk etmesi muhtemeldir. Buna paralel olarak, üstbilişin özel bir türü olan ahlaki üstbilişin sözü edilen bu artmış farkındalık ile hem doğrudan hem de genel üst biliş ile ilişkili olması beklenmektedir. Ayrıca her üç değişkenin de ahlaki farkındalık ile ilişkili olması yukarıda sözü edilen ilişkiler ağı göz önüne alındığında yine bu çalışmanın beklentileri arasındadır.

Daha önce de belirtildiği gibi yardım davranışı açısından bir ihtiyacı fark etmek oldukça önemli bir aşamadır. Benzer bir durum diğer ahlaki davranışlar için de söz konusudur. Ahlaki davranış ya da özgeci eylemlerin arka planında yer alan algılama, farkında olma, muhakeme, yargilama ya da karar verme gibi bilişsel süreçlerin aydınlatılması ahlak psikolojisi yazını açısından oldukça önemlidir. Bu bağlamda çalışmanın özgün yönü, söz konusu bilişsel süreçler içinde bilinçli farkındalık, üstbiliş ve ahlaki farkındalık arasındaki ilişkilerin açıklığa kavuşturulması olacaktır.

Çalışmanın sözü edilen beklentileri ışığında ortaya çıkan çalışma hipotezlerinden oluşan bir dizi aracılık modeli Şekil 1'de sunulmuştur. Şekil üzerinde gösterilen tüm ilişkilerin pozitif yönde olması beklenmektedir.

Şekil 1. Araştırma hipotezlerinden oluşan model

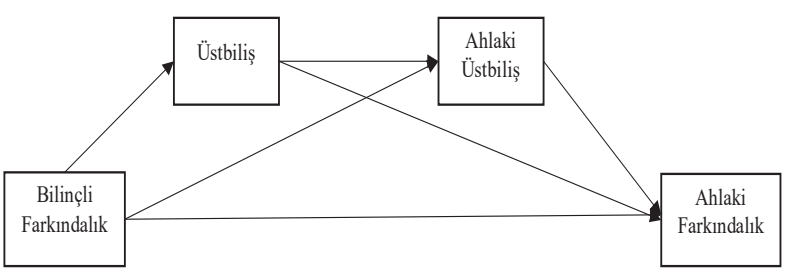

\section{YÖNTEM}

\subsection{Katılımcilar}

Bu çalışmanın örneklemi yaşları 18 ile 42 arasında değişen (Ort= 24.10, SS= 3.83) çoğunluğu lisans öğrencisi $(\% 77,3)$ olmak üzere farklı eğitim düzeylerinden 220 kişiden oluşmaktadır (bk. Çizelge 1). Katılımcıların $184^{\prime}$ ü kadın $(\% 83,6), 36$ 'sı ise $(\% 16,4)$ erkektir.
Çizelge 1. Katılımcıların demografik özellikleri

\begin{tabular}{clcc} 
& & $\mathrm{N}$ & $\%$ \\
\hline \multirow{2}{*}{ Cinsiyet } & Kadın & 184 & 83,6 \\
\cline { 2 - 4 } & Erkek & 36 & 16,4 \\
\hline \multirow{3}{*}{$\begin{array}{c}\text { Eüitim } \\
\text { Düzeyi }\end{array}$} & İlk Öğretim & 1 &, 5 \\
\cline { 2 - 4 } & Lise & 15 & 6,8 \\
\cline { 2 - 4 } & Lisans & 170 & 77,3 \\
\cline { 2 - 4 } & Yüksek Lisans & 29 & 13,2 \\
\cline { 2 - 4 } & Doktora & 5 & 2,3 \\
\hline
\end{tabular}

\subsection{Veri Toplama Araçları}

Bilinçli Farkındalık Ölçeği. On beş maddeden oluşan ve 6 'll likert tipinde puanlanan ( $1=$ "hemen hemen her zaman"; 6= "neredeyse hiçbir zaman") Bilinçli Farkındalık Ölçeğinin (Brown ve Ryan, 2003) Türkçe uyarlaması Çatak (2012) tarafından yapılmıştır. Ölçekte "Ne yaptığımın pek farkında olmadan otomatik yaşıyor gibiyim" ya da "Kendimi dikkatimi vermeden bir şeyler yaparken bulurum" gibi maddeler yer almaktadır. Türkçe uyarlama çalışmasından elde edilen iç tutarlılık katsayısı .85 olarak hesaplanmıştır. Ölçekten alınan yüksek puanlar daha yüksek bilinçli farkındalık düzeyine işaret etmektedir.

Üstbiliş Ölçeği. Dörtlü likert tipinde derecelendirilen (1= "Kesinlikle katılmıyorum"; 4= "Kesinlikle katıl1yorum") Üstbiliş Ölçeği (Cartwright-Hatton ve Wells, 1997) Türkçe'ye Tosun ve Irak (2008) tarafından uyarlanmıştır. Ölçek; toplam puan ile tek boyutlu olarak kullanılabilmekle birlikte "olumlu inançlar", "bilişsel güven", "kontrol edilemezlik ve tehlike", "bilişsel farkındalık" ve "düşünceleri kontrol ihtiyacı" olmak üzere beş boyuttan oluşmaktadır. Otuz maddelik ölçekten alınan puanlar 30 ile 120 arasında değişmekte ve yüksek puanlar patolojik ölçüde bir üstbiliş faaliyetini işaret etmektedir, zira ölçek psikopatolojilerdeki üstbilişsel faaliyetleri ölçmeyi amaçlamaktadır. Bununla birlikte bu çalışmadaki kuramsal temel dikkate alındığında üstbilişin normal işlevleri olan bilişlerin farkında olmak, diğer bir ifadeyle "düşünmeyi düşünmek" yönünü içeren genel tanımı esas alınmıştır. Bu nedenle ölçeğin tümü bütün olarak uygulanmış ancak analizlerde "bilişsel farkındalık" alt boyutu puanları kullanılmıştır. Bu alt boyutta "Bir problem üzerinde düşünürken zihnimin nasıl çalıştığının farkındayımdır" ya da "Düşüncelerimi izlerim" gibi maddeler yer alır. Bu alt boyut dikkatin ve düşüncelerin izlenmesi, düşüncelerin farkında olmak ile ilgili 5 maddeden oluşmaktadır. Türkçe geçerlik ve güvenilirlik analizle- 
rinde iç tutarlılık katsayısı toplam ölçek için .86 olarak bildirilmiştir.

Ahlaki Üstbiliş Ölçeği. Ahlaki Üstbiliş Ölçeği'nin (McMahon ve Good, 2015) Türkçe uyarlaması yapılmış ve ahlaki üstbilişi ölçmek amacıyla kullanılan 20 madde ve dört faktörden oluşan geçerli ve güvenilir bir ölçek olduğu belirlenmiştir (Çelik ve Sarıçam, 2018; Sönmez vd., 2018). Bununla birlikte toplam puanların tek boyutlu olarak kullanılmasının uygun olduğu bildirilmektedir. Ölçek, 6'lı likert tipinde puanlanmaktadır (1= "Kesinlikle katılmıyorum"; 6= "Kesinlikle katılıyorum") ve ölçekten alınan yüksek puanlar yüksek düzeyde ahlaki üstbilişe işaret etmektedir. Bütün ölçek için iç tutarlılık katsayısı .89 olarak bulunmuştur. "Ahlaki bir karara varmadan önce olası birkaç eylem biçimini göz önüne alırım" ya da "Ahlaki karar verirken güçlü ve zayıf yanlarımı bilirim” gibi ifadeler ölçek maddelerine örnek olarak verilebilir.

Ahlaki Farkındalık Senaryoları. Çalışmada katılımc1lara ahlaki açıdan uygun olan ya da olmayan durumlar içeren bir hikâye sunulmuş ve "Lütfen bu hikâyede ahlaki açıdan olumlu ve olumsuz gördüğünüz tüm durumları maddeler halinde listeleyin" yönergesi ile fark ettikleri olumlu ve olumsuz tüm ahlaki durumları listelemeleri istenmiştir. Hikayedeki olumlu ve olumsuz maddelerin sayısı ayrı ayrı kullanılabilmekle birlikte bu çalışmada bir toplam ahlaki farkındalık puanı olarak olumlu ve olumsuz durumların toplam sayısı temel alınmıştır. Ahlaki farkındalık senaryosu EK 1'de sunulmuştur.

\subsection{Prosedür}

$\mathrm{Bu}$ çalışmanın veri toplama aşamasına geçilmeden önce Selçuk Üniversitesi Edebiyat Fakültesi Bilimsel Etik Değerlendirme Kurulundan etik uygunluk onayı alınmıştır. Araştırma soruları katılımcılara sosyal medya platformları ya da anlık mesajlaşma uygulamaları aracılığıyla dijital ortamda iletilmiştir. Katılımcılara anketleri yanıtlamadan önce bilgilendirilmiş onam formu sunulmuş ve katılım gönüllülük esasına göre devam etmiştir.

\subsection{Analiz Stratejisi}

Çalışma hipotezlerinden oluşan modeli test etmeden önce tanımlayıcı istatistikler ve değişkenler arasındaki korelasyon değerleri IBM SPSS 20 paket program aracılığıyla analiz edilmiştir. Korelasyon değerleri doğrultusunda sonuç değişkeni olarak ahlaki farkındalık değişkeninin çalışma değişkenleri ile korelasyon göstermemesi (bk. Çizelge 3) üzerine modelden çıkarılmıştır. Yeni oluşturulan tek aracılı model SPSS üzerinde çalıştırılan Proses Makro eklentisi ile proses yönteminde tanımlanan model 4 ile analiz edilmiştir (Hayes, 2018). Yine korelasyon değerleri doğrultusunda test edilen modelde eğitim düzeyi kovaryant değişken olarak tanımlanmış ve bootstrap değeri 5000 olarak belirlenmiştir.

\section{SONUÇLAR}

Araştırmanın hipotezlerini test etmeden önce çarpıklık, basıklık katsayıları ve histogram grafiklerinin incelenmesi neticesinde veri setinin parametrik testlere uygun olduğu anlaşılmıştır. Çalışma değişkenlerine

Çizelge 2. Çalışma değişkenlerine ait tanımlayıcı istatistikler

\begin{tabular}{|c|c|c|c|c|c|c|c|c|c|c|}
\hline Değişkenler & $\mathbf{N}$ & Ort. & SS & $\boldsymbol{\alpha}$ & Min. & Mak. & $\begin{array}{l}\text { Potansiyel } \\
\text { Min.- } \\
\text { Mak. }\end{array}$ & $\begin{array}{l}\text { Uzam } \\
\text { (range) }\end{array}$ & $\begin{array}{l}\text { Çarpıklık } \\
\text { (Skew) }\end{array}$ & $\begin{array}{c}\text { Basıklık } \\
\text { (Kurtosis) }\end{array}$ \\
\hline Eğitim & 220 & 3.10 & .55 & - & 1 & 5 & $1-5$ & 4 & .73 & 3.49 \\
\hline Yaş & 220 & 24.10 & 3.83 & - & 18 & 42 & - & 24 & 1.73 & 5.80 \\
\hline $\begin{array}{l}\text { Bilinçli } \\
\text { Farkındalık }\end{array}$ & 220 & 4.04 & .76 & .86 & 1.93 & 5.60 & $1-6$ & 3.67 & -.24 & -.38 \\
\hline $\begin{array}{l}\text { Üstbiliş (bilişsel } \\
\text { farkındalık) }\end{array}$ & 220 & 2.90 & .47 & .64 & 1 & 4 & $1-4$ & 3 & -.62 & 1.65 \\
\hline Ahlaki Üstbiliş & 220 & 4.38 & .68 & .91 & 1.70 & 6 & $1-6$ & 4.3 & -1.08 & 2.78 \\
\hline $\begin{array}{l}\text { Olumlu Ahlaki } \\
\text { Farkındalık }\end{array}$ & 220 & .96 & .84 & - & 0 & 5 & - & 5 & 1.04 & 2.48 \\
\hline $\begin{array}{l}\text { Olumsuz Ahlaki } \\
\text { Farkındalık }\end{array}$ & 220 & 1.91 & 1.45 & - & 0 & 9 & - & 9 & 1.25 & 3.03 \\
\hline $\begin{array}{l}\text { Ahlaki } \\
\text { Farkındalık }\end{array}$ & 220 & 2.87 & 1.74 & - & 0 & 14 & - & 14 & 1.62 & 6.9 \\
\hline
\end{tabular}


ilişkin tanımlayıcı istatistikler Çizelge 2'de sunulmuştur.

Araştırma değişkenleri arasındaki korelasyonlara bakıldığında önerilen model doğrultusunda temel değişkenler arasında anlamlı korelasyonlar görülmektedir. Buna göre bilinçli farkındalık üst biliş $(\mathrm{r}=.34, \mathrm{p}<.01)$ ile ve ahlaki üst biliş ( $\mathrm{r}=.18, \mathrm{p}<.01)$ ile pozitif yönlü anlamlı ilişki içindedir. Üstbiliş ve ahlaki üstbiliş ( $\mathrm{r}=.43$, $\mathrm{p}<.01$ ) arasında da pozitif yönlü anlamlı ilişki gözlenmektedir. Ayrıca eğitim düzeyi ahlaki üstbiliş ( $\mathrm{r}=.17$, $\mathrm{p}<.05)$, olumsuz ahlaki farkındalık $(\mathrm{r}=.16, \mathrm{p}<.05)$ ve toplam ahlaki farkındalık $(\mathrm{r}=.16, \mathrm{p}<.05)$ ile pozitif yönde anlamlı ilişkilidir. Tüm değişkenler arasındaki korelasyonlar Çizelge 3'te sunulmuştur.

Araştırma hipotezlerinden oluşan model Proses yöntemi ile analiz edilmiş ve geçerli anlamlılık değerleri elde edilmiştir. Buna göre üstbilişin sonuç değişkeni olduğu modelde $(\mathrm{R} 2=.12, \mathrm{~F}(2-217)=14.32, \mathrm{p}<.01)$ bilinçli farkındalık üstbilişi anlamlı olarak yordamaktadır $(\square=.34, \mathrm{p}<.01)$. Nihai modelde ise $(\mathrm{R} 2=.22$, $\mathrm{F}(3-216)=20.11, \mathrm{p}<.01)$ üstbiliş $(\mathrm{\square}=.43, \mathrm{p}<.01)$ ahlaki üstbilişi anlamlı olarak yordamakta iken bilinçli farkındalık ile ahlaki üstbiliş arasında anlamlı ilişki bulunmamıştır (bk. Şekil 2). Analizde eğitim düzeyi- nin ahlaki üstbiliş ile anlamlı korelasyonu nedeniyle kovaryant değişken olduğu belirtilmişti. Ahlaki üstbiliş açısından eğitim etkisi de anlamlıdır ( $\square=.19$, p $<.01)$.

\section{TARTIŞMA}

Araştırma hipotezlerinden oluşan model (bk. Şekil 1) korelasyon analizlerinden elde edilen veriler doğrultusunda ahlaki farkındalığın modelden çıkarılmasıyla bir dizi aracılık ilişkisi önerisinden yalnızca tek aracı değişkenli bir modele dönüştü. Bu model üzerinden yapılan analizlerden elde edilen bulgular aracilık etkisini doğrulamaktadır. Beklendiği gibi bilinçli farkındalık üstbilişe, üstbiliş de ahlaki üstbilişe pozitif yönde anlamlı olarak katkı sağlamaktadır. Bununla birlikte bilinçli farkındalıktan ahlaki üstbilişe giden yolun anlamlı olmaması nedeniyle bu aracılık modelde önerildiği şekliyle kısmi aracılık değil tam arac1liktır. Bununla birlikte Baron ve Kenny'nin tam aracılık-kısmi aracılık ayrımını Zhao ve diğerleri (2010) yeniden sınıflandırmışlardır. Bu çalışma bulgularında doğrulanan model, Zhao ve diğerlerinin sınıflandırmasında sadece dolaylı aracılık (Indirect-only mediation) etkisine karşılık gelmektedir.

Çizelge 3. Araştırma değişkenleri arasındaki korelasyonlar

\begin{tabular}{|c|c|c|c|c|c|c|c|c|}
\hline & 1 & 2 & 3 & 4 & 5 & 6 & 7 & 8 \\
\hline 1. Eğitim & 1 & & & & & & & \\
\hline 2. Yaş & $.24 * *$ & 1 & & & & & & \\
\hline $\begin{array}{l}\text { 3. Bilinçli } \\
\text { Farkındalık }\end{array}$ & .02 & .09 & 1 & & & & & \\
\hline 4. Üstbiliş & -.05 & -.04 & $.34 * *$ & 1 & & & & \\
\hline 5. Ahlaki Üstbiliş & $.17^{*}$ & .12 & $.18^{* *}$ & $.43 * *$ & 1 & & & \\
\hline $\begin{array}{l}\text { 6. Olumlu ahlaki } \\
\text { farkındalık }\end{array}$ & .04 & -.05 & -.10 & -.03 & -.12 & 1 & & \\
\hline $\begin{array}{l}\text { 7. Olumsuz ahlaki } \\
\text { farkindalık }\end{array}$ & $.16^{*}$ & .04 & .12 & -.03 & -.01 & .10 & 1 & \\
\hline 8. Ahlaki farkındalık & $.16^{*}$ & .01 & .05 & -.04 & -.06 & $.56^{* *}$ & $.88^{* *}$ & 1 \\
\hline$* * \mathrm{p}<0.01$ & & & & & & & & \\
\hline
\end{tabular}

Şekil 2. Araştırmada test edilen hipotezlerden oluşan model

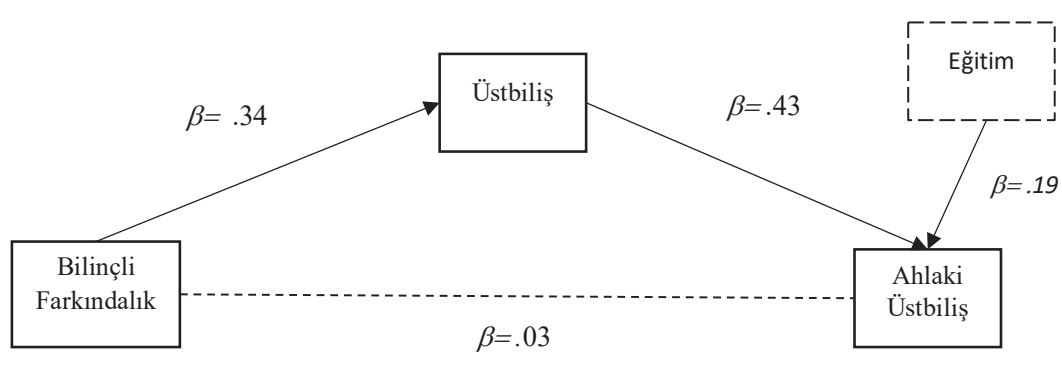


Bulguları değerlendirmeden önce araştırma modelindeki değişikliğin temel nedeni olan ahlaki farkındalık değişkeninin analiz dışı kalmasını yorumlamak gereklidir. Olası nedenlerden biri ölçümler arasındaki nitelik farkı olabilir zira diğer değişkenler öz bildirime dayalı ölçme araçlarından elde edilen verileri yansıtmaktayken ahlaki farkındalık bir tür performans testidir. Diğer değişkenlerden farklı olarak ahlaki bir senaryodaki olası ahlaki durumların farkına varmaları beklenmiştir. Ahlaki üstbiliş ve ahlaki farkındalık tanımları gereği oldukça yakın kavramlar olmasına karşın ilişkili bulunmaması ölçümler arası bu farklılıktan kaynaklanmış olabilir. Zira ahlak çalışmalarında öz bildirime dayalı verilerle dolaylı ölçümlerin her zaman örtüşmediği çalışmalar gözlenmektedir (bk. Arslantürk ve Harput, 2020; Saroglou vd. 2005).

Tüm bunların yanında, nihai modele bakıldığında, bilişsel farkındalık ahlaki üstbiliş ile genel üstbiliş arac1lığıyla ilişkili görünmektedir. Bu bulgu söz konusu hipotezin çıkış noktası olarak bireylerin kendi süreçlerine, çevresinde olup bitenlere, anlık değişimlere odaklanma; "şimdi" ve "burada" olanı takip edebilme, yakalayabilme özelliğinin aynı zamanda kendi zihnine de odaklanabilmeyi sağladığını akla getirmektedir. Bu varsayıma göre kendi zihninin, aklından geçenlerin farkında olan insan ahlaki düşüncelerinin, ahlaki karar verme süreçlerinin, ahlaki konulara ne ölçüde dikkat verebildiğinin de farkına varmaktadır. $\mathrm{Bu}$ bulgu ilgili yazına da önemli bir katkı sunmaktadır zira ahlaki bilişsel süreçler arasındaki ilişkilere yönelik çalışmaların sayısı azdır. Örneğin bu çalışmada desteklenen model Ruedy ve Schweitzer'in (2010) bulgularını bir adım öteye taşımaktadır. Buna göre araştırmacılar bilinçli farkındalığın ahlaki kararlarla ilişkisini ortaya koymuşlardı. Bu çalışmanın bulguları ile birlikte değerlendirildiğinde bilinçli farkındalığın ahlaki akıl yürütme süreçlerinde hangi bilişsel mekanizmalarla temas halinde olduğuna ilişkin zihnimizde bir resim canlanabilir.

Tüm bunların ötesinde bu çalışmanın bazı sınırlılıklarını göz önünde bulundurmak gerekir. Öncelikle bu çalışma Koronavirüs salgını esnasında yürütüldüğünden veri toplama işlemi dijital ortamda gerçekleşmiştir. Özellikle ahlaki farkındalık senaryosuna verilen yanıt sayısı kâğıt kalem testi, bilgisayar ya da akıllı telefon üzerinden yanıtlamaya göre farklılaşabilir. Ayrıca çalışma örnekleminin ağırlıklı olarak kadın katılımcılardan oluşması cinsiyet karşılaştırmasına im- kân tanımamıştır. Gelecekteki çalışmalarda deneysel manipülasyonlar ve performans ölçümü gibi dolaylı ölçümlerin bir arada kullanıldığı daha geniş kapsamlı araştırmalarla bu çalışmanın bulguları bir adım öteye taşınabilir.

\section{KAYNAKÇA}

AKARSU, B. (1975). Felsefe terimleri sözlüğ̈̈. Türk Dil Kurumu Yayınları. ARSLANTÜRK, G. \& HARPUT, D. (2020, çevrimiçi görünüm). Prosociality, religiosity and values in adolescence: comparing the impact of religious and general schooling in Turkey. Journal of Beliefs \& Values, 1-15. https:// doi.org/10.1080/13617672.2020.1848150

BATSON, D. (2011). Altruism in Humans. Oxford University Press.

BROWN, K. W. \& RYAN, R. M. (2003). The benefits of being present: mindfulness and its role in psychological well-being. Journal of Personality and Social Psychology, 84, 822-848.

BUTTERFIELD, K. D., TREVIÑO, L. K. \& WEAVER, G. R. (2000). Moral awareness in business organizations: Influences of issue related and social context factors. Human Relations, 53(7), 981-1018.

CARTWRIGHT-HATTON, S. \& WELLS, A. (1997). Beliefs about worry and intrusions: The Meta-Cognitions Questionnaire and its correlates. Journal of Anxiety Disorders, 11(3), 279-296.

CHERUVALATH, R. (2019). Does studying 'ethics' improve engineering students' meta moral cognitive skills? Sci Eng Ethics, 25, 583-596, https:// doi.org/10.1007/s11948-017-0009-x

CATAK, P. D. (2012). The Turkish version of mindful attention awareness scale: Preliminary findings. Mindfulness, 3,1-9.

ÇELIK İ. \& SARIÇAM, H. (2018, Mart). Ahlaki Üstbiliş Ölçeği: Türkçeye Uyarlama, Geçerlik ve Güvenirlik Çalışması. IKSAD 1. Uluslararası Sosyal Bilimler Kongresi, Mardin, Türkiye. https://doi.org/10.13140/ RG.2.2.19068.85126

DARLEY, J. M., \& BATSON, C. D. (1973). “From Jerusalem to Jericho”: A study of situational and dispositional variables in helping behavior. Journal of Personality and Social Psychology, 27(1), 100-108.

DRUMWRIGHT, M., PRENTICE, R. VE BİASUCCI, C. (2015). Behavioral Ethics and teaching ethical decision making. Journal of Innovative Education, 13(3), 431-458.

DURUK, Ü., FIRAT, E. \& AKGÜN. A. (2020). Turkish Moral Metacognition Scale (TMMS): The study of adaptation, validation and reliability. International Online Journal of Educational Sciences, 12 (3), 153-163.

GOLDSTEIN, E. B. (2013). Bilişsel psikoloji (çev. O. Gündüz). Kaknüs Yayınları

HAYES, A. F. (2018). Introduction to mediation, moderation, and conditional process analysis: A regression-based approach (2nd edition). The Guilford Press

LANGER, E. (2007). "Mindfulness and mindlessness". R. F. Baumeister ve K. D. Vohs (Ed.), Encyclopedia of Social Psychology içinde (s. 572-574). SAGE Publications.

MACLIN, O. H. (2007). “Metacognition”. R. F. Baumeister ve K. D. Vohs (Ed.), Encyclopedia of Social Psychology içinde (s. 564-566). SAGE Publications.

MATSUMOTO, D. (2009). The cambridge dictionary of psychology. Cambridge University Press

MCMAHON, J. M. \& GOOD, D. J. (2015). The Moral Metacognition Scale: Development and validation. Ethics \& Behavior, 26(5), 357-394. Doi:10.10 $80 / 10508422.2015 .1028548$

NARVAEZ, D. (2010). Moral Complexity. Perspectives on Psychological 
Science, 5(2), 163-181. https://doi.org/10.1177/1745691610362351

RUEDY, N. E. \& SCHWEITZER, M. E. (2010). In the moment: The effect of mindfulness on ethical decision making. Journal of Business Ethics, 95(1), 73-87.

SAROGLOU, V., PICHON, I., TROMPETTE, L., Verschueren, M. \& Dernelle, R. (2005). Prosocial behavior and religion: new evidence based on projective measures and peer ratings. Journal for the Scientific Study of Religion, 44(3), 323-348. https://doi.org/10.1111/j.1468-5906.2005.00289.x

SCHWARTZ, S. H. (1977). Normative influences on altruism. L. Berkowitz (Ed.), Advances in Experimental Social Psychology içinde (s. 221-278). Academic Press.

SÖNMEZ, S., SARIÇAM, H. \& ÇELIKK İ., (2018, Mart). Ahlaki üstbiliş, makyavelist kişilik ve maneviyat arasındaki ilişki. Uluslararası Bilim ve Ĕgitim Kongresi, 23-25 Mart, Afyon, Türkiye.

STREeT, M. D., DOUGLAS, S. C., GEIGGER, S. W. \& MARTINKO, M. J. (2001). The impact of cognitive expenditure on the ethical decision-making process: The cognitive elaboration model. Organizational Behavior and Human Decision Processes, 86(2), 256-277. https://doi.org/10.1006/ obhd.2001.2957

TOSUN, A. \& IRAK, M. (2008). Üstbiliş ölçeği-30'un Türkçe uyarlaması, geçerliği, güvenirliği, kaygı ve obsesif-kompülsif belirtilerle ilişkisi. Türk Psikiyatri Dergisi, 19(1), 67-80.

VANDENBOS, G. R. (2015). APA dictionary of psychology. American Psychological Association.

ZHAO, X., LYNCH JR, J. G. \& CHEN, Q. (2010). Reconsidering Baron and Kenny: Myths and truths about mediation analysis. Journal of Consumer Research, 37(2), 197-206.

\section{EK 1. Ahlaki Farkındalık Senaryosu}

Bay A. bir gün ofise her zamankinden erken gelmişti. Mesai henüz başlamadığı için kimse yoktu. O sırada müdürün odasında bir hareket fark etti. Hızla odaya doğru gidip kapıyı açtığında iş arkadaşını kasayı kurcalarken yakaladı. Öfkeli bir sesle ona bunu neden yaptığını sordu. Arkadaşı çocuğunun hasta olduğunu, tedavi için paraya ihtiyaç duyduğunu söyledi. Müdüre durumu arz ettiğinde üzgün olduğunu ama yardımcı olamayacağını ifade ettiğini anlattı. Bay A. bunun üzerine arkadaşına onu gördüğünü kimseye anlatmayacağını ama bunu yapmasına da izin vermeyeceğini söyledi. Arkadaşı çaresizce odadan çıktı. Müdür odaya geldiğinde odadaki karışıklığı fark edip durumu Bay A.'ya sordu. Bay A. ise odayı temizleyen temizlik görevlisinin o gün biraz özensiz çalışmış olabileceğini bunun dışında bir durum olmadığını söyleyerek arkadaşını ele vermedi.

Lütfen bu hikâyede ahlaki açıdan olumlu ve olumsuz gördüğünüz tüm durumları maddeler halinde listeleyin. 